\title{
The Benefits of Equity and English: Special Needs Inclusion in Japanese Education
}

\author{
Catori Sarmiento \\ Tokyo Department of Education, Japan
}

\begin{abstract}
This paper explores the best practices of how to include students with special needs into mainstream Japanese Public Education classrooms with a focus on the concept of English language acquisition, equity, the Least Restrictive Environment, and the concept of holistic learning. The research covers current and past social and cultural dogmas that must be overcome, the steps to implement inclusion in a unique setting. For the purposes of this, the research has been conducted in areas of the Tokyo Prefecture Public and Social Education systems.
\end{abstract}

\section{Introduction}

Understanding the unique Japanese social and cultural concepts is the impetus to fostering positive changes in integrating students with special needs. Foremost among these is the concept of 和, “wa", that is, the social harmony in which community is valued over personal interests [1] and that of "The nail that sticks up gets hammered", which is a Japanese proverb that, in essence, portrays the desire for social conformity; everyone should be treated exactly the same. In the classroom, the students are the nails, and the teacher is the hammer.

While this strict method may work with mainstream students, the concept is impractical with the changing dynamics in public schools and especially when working with those with special needs. As such, educational policy changes in 2003 and then further in the "School Education Law" in 2007 [2] meant that regular schools could accept more students with special needs. Since that time, there has been a rise in the student population with designated disabilities.

As Japan has made improvements to the educational system, there remains a systemic separation of special needs students into either a designated "special needs school", or otherwise in a mainstream school with "special classrooms" or "resource rooms" and, as such, there has been a slow movement towards practical inclusion in public and private schools. In a culture which values conformity, it is especially difficult for students with special needs to receive the environment that they require.

For educators to have an active role in teaching students with special needs, they must prepare a classroom based on the concept of equity, which focuses on providing each student with the tools they need to be successful, and implementing a comprehensive English language program for the purposes of speech therapy and interpersonal social interaction.

\section{Inclusion}

In the dissertation "Disabilities in Cultural Context: Providing Social and Emotional Support for Japanese Children with Developmental Disabilities in Regular Classrooms", Ms. Kayama, presents similar findings in which the local schools show numerous adaptations in regards to barrier-free environmental accountabilities, pensions, daily living, and the like, while omitting actual concrete plans for integration in favor of leaning on a vague concept of inclusion [3]. Yet, while the Tokyo Metropolitan Government has issued declarations in favor of equality and open access to public education, it was not until as recently as 2016 that districts in Tokyo have begun integrating students with special needs into mainstream classrooms, with the number enrolled in special needs schools and compulsory public education at 267,000 students [4]. Yet, what is undertaken in proclamation and practice varies greatly.

According to interviews taken with Hamura and Ome district schools, students with special needs attend mainstream classes at their or their families' personal discretion [5]. In most cases, the local district offers few choices for the student, limited to a special needs classroom, a separate special needs school, and mild inclusion into the mainstream classroom. If the students join the mainstream class, they are able to do so half-time, in a special needs classroom, or in the regular classroom if the school employs an assistant teacher. Schools also rely on guidance classrooms, which are separate rooms within the school to accommodate those students with special needs. However, if schools do not have one available, the students are sent off-campus [6].

As schools present these options to the students and their families, what can often occur is continued classroom and social segregation. The students may be in attendance in the mainstream classroom but are not met on their individualized, developmental needs. This separation has continued with regards to "Special Support Schools".

The current social hurdle is one where any student who shows a disability, however mild, may be 
classified into a special school when a Least Restrictive Environment may be more beneficial. The outcome of attending a special education school yields a drastic result. For a mainstream student who attends school until graduation, they can expect to receive an official diploma that will transfer to a university or job training school.

This is not true of special education schools, as they are in a separate vocational class. As such, students graduating from a special education school receives a Tokubetsu kyōiku sotsugyō shōsho, Certificate of Special Needs Diploma, that is not accepted by universities. Should a student wish to attend a university, they would then have to take a GED equivalency examination, which are done by a quota system [7]. Such an obstacle creates a clear social divide where students with special needs are essentially barred from higher education or highskills occupations.

Since students in special needs schools are grouped together regardless of their spectrum, from mild (Dyslexia) to severe (Schizophrenia) and are often labeled under the broad term of "Intellectually Disabled", this approach limits the potential of students who may exceed academic expectations. Since there is such a wide spectrum of disabilities, each student must be treated individually according to their needs. According to the Ministry of Education, Culture, Sports, Science, and Technology Japan, those with Autism or Intellectual disabilities make up over ninety-four percent of students from primary to middle school. This creates a unique situation where classroom integration is concerned and, depending on the spectrum of the students, behavior modification may take a considerable amount of effort.

Such efforts can lead to a cohesive, positive experience only if the classroom is focused on the best, holistic learning environment for all students, including, and especially those with special needs. Taking the environment into perspective is one of the first steps to classroom adaptations and what has had a continual, positive, change has been small classroom sizes. When the number of students in a classroom is reduced, it allows for more opportunities for quality, teacher-student interactions with teachers having the ability to be more responsive to student learning [7]. This methodology has been reflected at a special needs school in Ome, Tokyo, called Seiho Gakuen. There, the school implemented a model of a smaller student class size in ratio to the teachers. At this special needs school, the number of students per class was at a maximum of ten, with each student being given the attention necessary to not only succeed in their learning experience, but also to provide a responsive environment that allowed for students to receive the individualized attention that they may require [8].
Yet, individualized learning need not be limited to segregated special needs schools or support classrooms. When each individual student is receiving the appropriate tools in the classroom, then the entire class as a whole can find success. One such method of unique classroom inclusion in Japanese schools is through English Language Education.

\section{Integration through English}

The inclusion of the English language into Japanese school curriculum has been in formal existence beginning 1998 and has continually expanded across schools and grade levels since that time, with the most recent, all-encompassing expansion occurring to meet the needs of a growing globalized world.

In 2013, the Tokyo Department of Education issued new secondary language guidance for public schools in order to address globalization. Public schools in Tokyo are transitioning to English Language as a formal subject by 2020, expanding English language education to primary schools and increasing the hours of English instruction [9]. In the public school environment, English Language courses may be conducted in a separate, inclusive classroom. Consequently, for special needs students who are segregated, English may be the only subject in which they are included into the regular classroom. This allows special needs students the opportunity to participate in a learning environment amongst their peers in a group setting.

The environment of an English language class also has the benefit of the presence of a co-teacher in the form of the Assistant Language Teacher (ALT) or a Japan Exchange in Teaching (JET) classroom instructor. With the student focus on the direct English instruction or lesson activities, the classroom teacher is better able to assist in an individualized plan for any special needs students. This environment lends itself to a mutually beneficial situation in which the regular students can learn how to interact with and include their differently abled and diverse peers while students with special needs can learn the essentials of social development. While social interaction is a difficulty for some students with special needs, it is also of great importance so that they are able to receive practice in a safe, secure environment that the English classroom can provide.

For students with intellectual disabilities, particularly those on the Autism spectrum who may typically be segregated in the special support classroom, attending the integrated English class may be their only opportunity to interact with their peers. Research has shown that the more opportunities special needs students have at social interaction, the better they can come to understand social cues, interpersonal relationships, expectations, and the understanding they need to interact with 
peers and teachers both inside and outside of the school environment [10]. Giving students more opportunities to practice their social skills can have wide-reaching outcomes not only for themselves, but also for their teachers, their families, and their communities.

In observations for this paper, a course of several English lessons at a Hamura public school were observed wherein there was a fifth grade elementary class with fourteen regular students and one with a diagnosed intellectual disability on the autism spectrum. The special needs student in particular normally attended the separated support classroom, with English being the sole opportunity for attendance in a regular classroom. In the initial lessons, the student remained largely non-verbal and refused to participate. In one incident, when the student was prompted to write by the teacher, the student responded by shrieking and tearing up the paper. A similar response was given to other students during a group activity and resulted in the rest of the class either ignoring or ostracizing the student, leaving the student to sitting or standing alone for the entirety of the lesson.

After a consultation with the ALT English teacher and the classroom teacher, it was decided that the special needs student be integrated into activities with the help of the teachers for support during class activities. During the next class, the lesson required role-playing as grocery store clerks and customers, using flashcards. Rather than expecting the student to participate in the same fashion as the regular students, both teachers were able to take turns encouraging the student to participate by acting as a classroom assistant. The student would help to organize the flashcards and when the lesson was over, to help move tables. Over the course of several class lessons, the student began saying a few words to fellow classmates, and even being given small, helpful, roles in a small group. Without the English class setting with the support of a secondary teacher, the student would not have had the opportunity to practice group social interaction or speaking skills.

\section{English as Speech Therapy}

As a language, English provides a unique circumstance for secondary language learners. The process of learning a new language may greatly assist students on the level that they are best able to meet through a variety of teaching techniques including positive reinforcement, least restrictive environment, intrinsic rewards, and whole-class instruction. Such instructional techniques are important for both special education students and students who are learning English, since learning a secondary language has been shown in recent studies to greatly increase critical thinking, speech, reading, writing, and executive functions in individuals with Autism Spectrum Disorders and developmental impairments [11].

Due to these changes in Japanese Education, it is important for professional educators to understand that English instruction is particularly beneficial to students with special needs. One of the prospective goals of English language teaching to students with developmental disabilities and special needs is to encourage nonverbal, illiterate, or functionally illiterate, students to develop forms of speech and communication. From a base of understanding is the nature of the Japanese language in contrast to the English language in terms of written and oral communication.

When learning Japanese, students are expected to become proficient in three different writing systems: hiragana, katakana, and kanji. The hiragana and katakana, or in combination, referred to as kana, systems are based on phonetic pronunciation, while kanji are logograms which represent morphemes. Given the nature of kanji, this can result in one kanji having two or more different pronunciations based on structural context alone. In daily life, kanji is then combined with hiragana and katakana in written communication.

These are the writing systems that students learn throughout their attendance in school, beginning in the lower grades with hiragana and katakana, and then transitioning to kanji as they reach higher grade levels, to eventually achieve proficiency in understanding the 2,136 required j oyō kanji, otherwise known as, "daily use", kanji. The ability to recognize and read Japanese is then compounded with the necessity of being able to legibly write in the different necessary forms.

Furthermore, each of the three writing systems uses a stroke style in which the order of each stroke is important. This is particularly noticed when there are similarly written kanji or kana with few stroke differences. Given that each kanji can range from one to thirty stokes, students with intellectual disorders can find the entire mental and physical act of learning the written language to be especially difficult, if not insurmountable.

In contrast, the English written language, while having grammar and roots based on a conglomeration of European Romance languages, has a singular writing system with the fundamental English alphabet consisting of 26 letters. And while there are countless letter and word compilations, the basic linguistic structure is less complicated.

The Japanese language is unique in that it is generally agglutinative. In juxtaposition, English in an analytic language. Consider that when the phonetics are contrasted, it is apparent that English uses considerably more phonemes than the Japanese language, with English having 44 and Japanese having 15 . There are also a great many more vowel 
and consonant variants in English as well as the use of stress, rhythm, and intonation. As such, the mere act of learning English phonics in itself is a form of mild speech therapy with Japanese Language speakers having to practice alternative tongue placements, mouth movements, and voice modifications than they are typically accustomed.

Since many persons with disabilities have significant difficulties with speech and language acquisition, such communication practices are paramount to student achievement. According to "Statistics on Education for Children with Disabilities in Japan", over seventy-one percent of students in schools have a speech and language disorder. Therefore, introducing English language coursework is beneficial as a basis for basic speech therapy.

Over the course of research for this paper, certain research interventions were undertaken at three special needs facilities located in Ome, Tokyo. The primary intervention strategies were with individualized behavior plans, social activities, and intensive lessons in English language speech patterns, specifically the focus on oral motor exercises, practicing phonics and monosyllables, and listening comprehension.

After a period of six months, the students were found to have increased their social skills as well as their basic communication abilities. In one case, a student who had been low verbal, learned to say "Fah" and "Pah", leading to the student speaking "Pan", or "bread" in Japanese. When interviewed about student success, one teacher reported that "Students who could not communicate using any Japanese could do it in English." and that the "Phonics is easier to hear and the lettering clearer and less complicated than Japanese." [12]. Higher functioning students were also found to have gained further independence. As Japanese transportation, supermarkets, and convenience stores have been increasing their use of the English language in signs and displays in order to accommodate tourists, students with special needs who have learned English have also found daily travel less confusing as they were able to comprehend daily social tasks. Similarly, students with attention difficulties were found to have lower instances of behavioral issues since they were given the opportunity for active participation and free expression.

\section{Equity When Meeting the Individual}

As students with special needs are increasingly mainstreamed into classrooms, there must be a positive social and academic support system that promotes equity. When interviewed as to whether local districts and special needs facilities promoted classroom inclusion, the answer was a resounding negative. This likely stems from the strong cultural adherence to social harmony and the aversion to individualization. However, as the larger Japanese culture, and educational environment, changes, so too does the manner in which students are taught.

Combining equity into special education has shown how beneficial individualized plans are to mainstreaming students into the Least Restrictive Environment and according to "Academic Achievement of Regular and Special Needs Students in Inclusive and Non-Inclusive Classroom Settings", students with special needs who were included into regular classrooms earned higher academic scores than their peers who were in non-inclusive classrooms [13]. Once individuals are nurtured, all students significantly benefit on an academic and emotional level - an outcome that coincides with the societal "wa" that remains paramount. When diversity is represented in the classroom, students can learn to work together with a variety of peers. And as cohesion continues throughout their youth, inevitably, this conviviality will extend to the larger Japanese society.

\section{Acknowledgements}

A great appreciation goes to Ms. Megumi Nagahama, who inspired me through her tireless commitment to teaching, and to the teachers and administrators in Ome and Hamura who continue to lead progression on Special Education in Japan.

\section{References}

[1] McDonald, A., (2017). Study Japanese Culture: "wa" (harmony) in Japanese and English language cultures. Scotland Study Centre. Retrieved from http://www.scotlandstudycentre.com/studyjapaneseculture-wa/ (July 30, 2018).

[2] Ministry of Education, Culture, Sports, Science and Technology. "Principles Guide Japan's Educational System", (2008). Retrieved from http://www.mext.go.jp/en/policy/education/overview /index.htm (July 12, 2019)

[3] Kayama, M. (2012). Disability in Cultural Context: Providing Social and Emotional Support for Japanese Children with "Developmental Disabilities" in Regular Classrooms. Graduate Dissertations and Theses at Illinois,125-129. Retrieved from http://hdl.handle.net/ 2142/29469 (June 16, 2018). (July 28, 2019)

[4] Special Needs Education Division, Elementary and Secondary Education Bureau, Ministry of Education, Culture, Sports, Science and Technology. Policy Trends on Special Needs Education in Japan. (2012). NISE Bulletin Vol. 11 March 2012. Retrieved from https://www.nise.go.jp/cms/resources/content/6232/2 0120611-152632.pdf (July 30, 2018).

[5] Nagahama, M. (2018) Personal Interview. 
[6] Book of the Disabled. (2008). Retrieved from http://www.ometky.ed.jp/shido/tokubetsushien gakkou.html, (7 June 2018).

[7] Nagahama, M. (2018) Personal Interview. [8] Seiho Gakuen 東京都立青峰. (2009). School Life 学校生活. Retrieved from http://www.seihosh.metro.tokyo.jp/site/zen/ (August 27, 2019)

[9] Ministry of Education, Culture, Sports, Science and Technology "Special Feature 1: 2020: Toward a

New Growth". (2013). Retrieved from http://www.mext. go.jp/b_menu/hakusho/html/hpab2

01301/detail/1360673.htm.

[10] Thng, Yi Xe. (2017). The Effects of Class Size on Student Behavioral Outcomes: The Role of TeacherStudent Interactions. Retrieved from http://nrs.harvard.edu/ urn3:HUL.InstRepos:3379724 6 (September 14, 2019).

[11] Griswold, A., (2016). For Children with Autism, Multiple Languages May Be a Boon. Scientific American. Retrieved from https://www.scientificamerican.com/ article/for-children-with-autism-multiple-languages-maybe-a-boon/, (June 27, 2018).

[12] Terayama, C., (2018). Personal Interview.

[13] Ekeh and Oladayo, (2013). Academic Achievement of Regular and Special Needs Students in Inclusive and NonInclusive Classroom Settings. European Scientific Journal March 2013 edition vol.9, No.8. Retrieved from https://eujournal.org/index.php/esj/article/viewFile/883/92 6. 